M. Adiels $\cdot$ M.-R. Taskinen $\cdot$ C. Packard $\cdot$

M. J. Caslake · A. Soro-Paavonen · J. Westerbacka •

S. Vehkavaara - A. Häkkinen - S.-O. Olofsson •

H. Yki-Järvinen · J. Borén

\title{
Overproduction of large VLDL particles is driven by increased liver fat content in man
}

Received: 5 July 2005 / Accepted: 18 October 2005 / Published online: 4 February 2006

(C) Springer-Verlag 2006

\begin{abstract}
Aims/hypothesis: We determined whether hepatic fat content and plasma adiponectin concentration regulate $\mathrm{VLDL}_{1}$ production. Methods: A multicompartment model was used to simultaneously determine the kinetic parameters of triglycerides (TGs) and apolipoprotein $\mathrm{B}$ (ApoB) in $\mathrm{VLDL}_{1}$ and $\mathrm{VLDL}_{2}$ after a bolus of $\left[{ }^{2} \mathrm{H}_{3}\right]$ leucine and $\left[{ }^{2} \mathrm{H}_{5}\right]$ glycerol in ten men with type 2 diabetes and in 18 non-diabetic men. Liver fat content was determined by proton spectroscopy and intra-abdominal fat content by MRI. Results: Univariate regression analysis showed that liver fat content, intra-abdominal fat volume, plasma glucose, insulin and HOMA-IR (homeostasis model assessment of insulin resistance) correlated with $\mathrm{VLDL}_{1} \mathrm{TG}$ and ApoB production. However, only liver fat and plasma glucose were significant in multiple regression models,
\end{abstract}

M. Adiels · S.-O. Olofsson · J. Borén

Wallenberg Laboratory, Gothenburg University,

Gothenburg, Sweden

M.-R. Taskinen · A. Soro-Paavonen

Division of Cardiology, University of Helsinki Biomedicum,

Helsinki, Finland

C. Packard · M. J. Caslake

Department of Pathological Biochemistry,

Glasgow Royal Infirmary,

Glasgow, UK

J. Westerbacka $\cdot$ S. Vehkavaara $\cdot$ H. Yki-Järvinen

Division of Diabetes, University of Helsinki,

Helsinki, Finland

A. Häkkinen

Department of Oncology, University of Helsinki,

Helsinki, Finland

J. Borén $(\square)$

Wallenberg Laboratory, Sahlgrenska University Hospital,

S-413 45 Göteborg, Sweden

e-mail: Jan.Boren@wlab.gu.se

Tel.: +46-31-3422949

Fax: $+46-31-823762$ emphasising the critical role of substrate fluxes and lipid availability in the liver as the driving force for overproduction of $\mathrm{VLDL}_{1}$ in subjects with type 2 diabetes. Despite negative correlations with fasting TG levels, liver fat content, and $\mathrm{VLDL}_{1} \mathrm{TG}$ and $\mathrm{ApoB}$ pool sizes, adiponectin was not linked to $\mathrm{VLDL}_{1} \mathrm{TG}$ or $\mathrm{ApoB}$ production and thus was not a predictor of $\mathrm{VLDL}_{1}$ production. However, adiponectin correlated negatively with the removal rates of $\mathrm{VLDL}_{1} \mathrm{TG}$ and ApoB. Conclusions/interpretation: We propose that the metabolic effect of insulin resistance, partly mediated by depressed plasma adiponectin levels, increases fatty acid flux from adipose tissue to the liver and induces the accumulation of fat in the liver. Elevated plasma glucose can further increase hepatic fat content through multiple pathways, resulting in overproduction of $\mathrm{VLDL}_{1}$ particles and leading to the characteristic dyslipidaemia associated with type 2 diabetes.

Keywords Apolipoprotein B - Compartmental modelling $\cdot$ Diabetes $\cdot$ Dyslipidaemia $\cdot$ Kinetics Stable isotope $\cdot$ Triglycerides $\cdot \mathrm{VLDL}$

Abbreviations ApoB: apolipoprotein B - ChREBP: carbohydrate responsive-element binding protein $\cdot$ FCR: fractional catabolic rate - FDCR: fractional direct catabolic rate - FTR: fractional transfer rate - HOMA-IR:

homeostasis model assessment of insulin resistance . PPAR: peroxisome proliferator activated receptor . SREBP1c: sterol regulatory element binding protein 1c TG: triglyceride

\section{Introduction}

Insulin resistance is associated with atherogenic dyslipidaemia characterised by high levels of triglyceride (TG)rich lipoproteins and their cholesteryl ester-rich remnant particles, low levels of HDL-cholesterol, and small dense LDL [1]. Previously, we reported that elevation of large VLDL particles is the major determinant of plasma TG levels in subjects with and without type 2 diabetes mellitus 
[2] and that the production rate of large $\mathrm{VLDL}_{1}$ particles is increased in type 2 diabetic patients [3]. Thus, in diabetic dyslipidaemia, overproduction of large VLDL particles seems to initiate a sequence of lipoprotein changes that increase the risk of atherosclerosis, including an increase in smaller LDL and a decrease in HDL particles. Importantly, these lipid abnormalities precede the clinical diagnosis of type 2 diabetes and may explain the 'ticking clock' hypothesis for macrovascular disease that develops long before diabetes. Thus, it is of great importance to elucidate the mechanisms behind the overproduction of large VLDL particles in diabetic dyslipidaemia.

Non-alcoholic fatty liver disease has emerged as a new component of the metabolic syndrome [4] and a predictor of type 2 diabetes [5-7]. In observational studies, liver fat content was associated with common features of insulin resistance (e.g. increased fasting insulin levels, high Cpeptide levels, glucose intolerance and intra-abdominal fat) both in patients with type 2 diabetes and in non-obese and moderately obese subjects without diabetes [4-6, 8, 9]. Therefore, the strong relationship between the hepatic fat content and hepatic insulin sensitivity is not surprising [8, $10,11]$. Liver fat content correlates closely with serum TGs, small dense LDL, and HDL-cholesterol [4, 8, 9]. Intriguingly, the fatty liver seems to exacerbate the dyslipidaemia in type 2 diabetic patients [10]. The mechanisms underlying the relationship between dyslipidaemia and liver fat have not been fully defined.

Excessive visceral fat appears to be a key factor in the development of the disturbed metabolism in type 2 diabetes. Intra-abdominal fat is considered the major source of hepatic NEFA released directly into the portal vein [12]. Thus, hepatic delivery of NEFA increases as the visceral fat compartment expands, and visceral adiposity has been reported to predict liver fat content $[9,10]$. Recent evidence suggests that dyslipidaemia is mainly attributable to increased intra-abdominal fat [13].

Adiponectin is an adipocyte-secreted hormone that acts as an anti-diabetic and anti-atherogenic adipocytokine [14, 15]. Decreased plasma concentrations of adiponectin, unlike all other adipocytokines, correlate negatively with liver fat content and liver insulin sensitivity [7, 9, 16]. Thus, the plasma adiponectin concentration is lower in human obesity and in other insulin-resistant states [14], suggesting that adiponectin may be an important marker of the metabolic syndrome. Emerging evidence suggests that adiponectin also influences lipid metabolism. Adiponectin levels correlate inversely with plasma TGs but positively with HDL-cholesterol levels and LDL size [4, 8, 9, 17-20]. Importantly, these relations persist even after adjustment for measures of overall obesity and visceral fat, consistent with a direct action of adiponectin on lipoprotein metabolism $[19,20]$. Thus, adiponectin may be a mediator between adipose tissue and the liver, influencing both glucose and lipid metabolism.

To determine whether hepatic fat content and plasma adiponectin concentration are key regulators of $\mathrm{VLDL}_{1}$ production, we used a novel multicompartment model that allows the kinetic parameters of TG and ApoB in $\mathrm{VLDL}_{1}$ and $\mathrm{VLDL}_{2}$ to be simultaneously determined after a bolus of $\left[{ }^{2} \mathrm{H}_{3}\right]$ leucine and $\left[{ }^{2} \mathrm{H}_{5}\right]$ glycerol [21]. Magnetic resonance proton spectroscopy was used to determine hepatic fat content and MRI to determine intra-abdominal and s.c. fat volumes. We studied both non-diabetic and type 2 diabetic subjects with different levels of insulin resistance, which permitted us to explore the effects of disturbances in lipid and glucose metabolism on VLDL kinetics over a wide range of liver fat and intra-abdominal fat content. Here we present the first human in vivo study on the relationship between liver and abdominal fat content and the production rate of $\mathrm{VLDL}_{1} \mathrm{TG}$ and ApoB. From the results we hypothesise that liver fat and plasma glucose are the major determinants of $\mathrm{VLDL}_{1} \mathrm{TG}$ and $\mathrm{ApoB}$ production rates.

\section{Subjects and methods}

\section{Subjects}

We studied ten subjects with type 2 diabetes and 18 nondiabetic subjects, all of whom were men of white European origin. The subjects were recruited by advertisement in local newspapers and from a Finnish database, Health 2000, which is a population-based cohort. All subjects underwent a physical examination and laboratory tests to exclude hepatic abnormalities (other than hepatic steatosis) and renal, thyroid and haematological abnormalities. Subjects with CHD, diabetic retinopathy or microalbuminuria, total cholesterol greater than $7.0 \mathrm{mmol} / \mathrm{l}$, TG greater than $5.0 \mathrm{mmol} / 1$, or BMI greater than $40 \mathrm{~kg} / \mathrm{m}^{2}$ were excluded. All non-diabetic subjects had lipid values representative of a Western population; three had IGT according to WHO criteria [22]. The diagnosis of type 2 diabetes was based on glucose tolerance tests according to WHO criteria [22] or on use of oral anti-diabetic medication. The age at onset of type 2 diabetes was at least 35 years. None of the subjects was taking lipid-lowering therapy or insulin. Four patients with type 2 diabetes and one non-diabetic subject were taking acetylsalicylic acid. Two patients with type 2 diabetes were treated with diet alone, one with diet and metformin, two with diet and sulfonylurea, and five with a combination therapy of sulfonylurea, metformin and diet. One patient with type 2 diabetes was using antihypertensive therapy (felodipine). The medications were continued throughout the study. The mean duration of diabetes was 7.0 years (range $0-13$ years). The study design was approved by the ethics committee of Helsinki University Central Hospital, and each subject gave written informed consent. All samples were collected in accordance with the Declaration of Helsinki. One subject did not have intra-abdominal or s.c. fat measured. Fifteen of the control subjects and six of the type 2 diabetic subjects were presented in a previous paper [3]. 
ApoB and TG turnover

Turnover of ApoB and TG was measured after an overnight fast. Particle composition and ApoB mass of the VLDL and $\mathrm{VLDL}_{2}$ fractions were determined $30 \mathrm{~min}$ before and 0 , 4 , and $8 \mathrm{~h}$ after a bolus injection of $\left[{ }^{2} \mathrm{H}_{3}\right]$ leucine and $\left[{ }^{2} \mathrm{H}_{5}\right]$ glycerol [21]. The subjects fasted until $17.00 \mathrm{~h}$, when the last blood sample was taken.

Kinetics analysis

Measured ApoB and TG pool sizes in $\mathrm{VLDL}_{1}$ and $\mathrm{VLDL}_{2}$ were converted into leucine and glycerol equivalents. The injected amount of $\left[{ }^{2} \mathrm{H}_{3}\right]$ leucine and $\left[{ }^{2} \mathrm{H}_{5}\right]$ glycerol, the leucine and glycerol pool sizes in $\mathrm{VLDL}_{1}$ and $\mathrm{VLDL}_{2}$, and the enrichment curves of leucine in plasma and leucine and glycerol in $\mathrm{VLDL}_{1}$ and $\mathrm{VLDL}_{2}$ were used as the data set for a multicompartment model that allowed simultaneous modelling of ApoB and TG kinetics as described [21]. The outputs from the model are the production rates and fractional catabolic rate (FCR) of $\mathrm{VLDL}_{1}$ and $\mathrm{VLDL}_{2}$ (the fractional loss of mass due to transfer and direct catabolism), the fractional direct catabolic rate (FDCR; the fractional loss of mass due to direct catabolism from $\left.\mathrm{VLDL}_{1}\right)$ and the fractional transfer rate (FTR; the fractional transfer from $\mathrm{VLDL}_{1}$ to $\mathrm{VLDL}_{2}$ ). In this model, we cannot distinguish between transfer from $\mathrm{VLDL}_{2}$ to intermediatedensity lipoprotein and direct catabolism of $\mathrm{VLDL}_{2}$ particles; hence they are represented by the FCR. The ApoB and TG production rates were calculated as $\mathrm{mg}$ day $^{-1} \mathrm{~kg}$ body weight ${ }^{-1}$. FCR, FDCR and FTR were calculated for both ApoB and TG as pools per day.

Isolation of lipoproteins and biochemical analyses

$\mathrm{VLDL}_{1}$ and $\mathrm{VLDL}_{2}$ were isolated from $8.4 \mathrm{ml}$ of plasma [23]. ApoB and TG concentrations in these lipoprotein fractions were measured in samples obtained at 0,4 and $8 \mathrm{~h}$. ApoB and TG pool sizes were calculated as the product of plasma volume (4.5\% of body weight) and the plasma concentration of ApoB and TG in $\mathrm{VLDL}_{1}$ and $\mathrm{VLDL}_{2}$. The leucine and glycerol contents of each pool were determined [21], and the TG, cholesterol, ApoB, glucose, insulin, NEFA, $\mathrm{HbA}_{1 \mathrm{c}}$ and protein concentrations in lipoprotein fractions were analysed as described [21]. LDL peak particle diameter (LDL size) was measured with $2-10 \%$ gradient polyacrylamide gel electrophoresis [24]. Serum adiponectin concentrations were measured with an ELISA kit (B-Bridge International, San Jose, CA, USA) that detected full-length peptides. The HOMA-IR (homeostasis model assessment for insulin resistance) was calculated from the fasting glucose and serum insulin concentrations as fasting insulin $(\mathrm{mU} / \mathrm{l}) \times$ fasting glucose $(\mathrm{mmol} / \mathrm{l}) / 22.5[25]$.

\section{Liver fat analysis}

Image-guided proton magnetic resonance spectroscopy was performed with a $1.5 \mathrm{~T}$ whole-body device (Magnetom

Table 1 Basic characteristics of the subjects

\begin{tabular}{|c|c|c|c|c|}
\hline & \multicolumn{2}{|c|}{ Non-diabetic subjects $(n=18)$} & \multicolumn{2}{|c|}{ Type 2 diabetic subjects $(n=10)$} \\
\hline & Mean \pm SD & Range & Mean \pm SD & Range \\
\hline Age (years) & $50 \pm 10$ & $25-64$ & $56 \pm 9$ & $37-67$ \\
\hline Weight (kg) & $82 \pm 9$ & $70-102$ & $94 \pm 9^{b}$ & $82-106$ \\
\hline BMI $\left(\mathrm{kg} / \mathrm{m}^{2}\right)$ & $26 \pm 2$ & $22-30$ & $30 \pm 4^{\mathrm{a}}$ & $23-35$ \\
\hline Liver fat $(\%)$ & $4 \pm 2$ & $1-10$ & $11 \pm 7^{\mathrm{c}}$ & $3-24$ \\
\hline Total abdominal fat $\left(\mathrm{cm}^{3}\right)$ & $3,845 \pm 1,270$ & $986-5,760$ & $5,103 \pm 942^{\mathrm{a}}$ & $3,441-6,539$ \\
\hline S.c. fat $\left(\mathrm{cm}^{3}\right)$ & $2,209 \pm 592$ & $946-3,313$ & $2,689 \pm 814$ & $1,614-4,334$ \\
\hline Intra-abdominal fat $\left(\mathrm{cm}^{3}\right)$ & $1,636 \pm 886$ & $40-3,341$ & $2,414 \pm 595^{\mathrm{a}}$ & $1,583-3,660$ \\
\hline Fasting serum glucose $(\mathrm{mmol} / \mathrm{l})$ & $5.9 \pm 0.6$ & $5.0-7.2$ & $8.5 \pm 1.5^{\mathrm{c}}$ & $6.8-11.7$ \\
\hline $\mathrm{HbA}_{1 \mathrm{c}}(\%)$ & & & $6.8 \pm 0.82$ & $6.1-8.1$ \\
\hline Fasting serum insulin (mU/1) & $7 \pm 3$ & $2.0-11.0$ & $10.1 \pm 3.6^{\mathrm{b}}$ & $5.5-14.7$ \\
\hline HOMA-IR & $1.8 \pm 0.8$ & $0.5-3.0$ & $3.9 \pm 1.6^{\mathrm{c}}$ & $1.9-6.5$ \\
\hline Serum adiponectin (mg/l) & $9.1 \pm 4.1$ & $4.6-18.9$ & $6.9 \pm 2.4$ & $3.4-11.0$ \\
\hline Serum ALT (U/1) & $26 \pm 7$ & $14-39$ & $36 \pm 14^{\mathrm{a}}$ & $24-72$ \\
\hline Serum NEFA $(\mu \mathrm{mol} / 1)$ & $558 \pm 89$ & $352-714$ & $656 \pm 152^{\mathrm{a}}$ & $377-876$ \\
\hline Plasma TG (mmol/l) & $1.5 \pm 0.61$ & $0.67-3.14$ & $2.00 \pm 0.77$ & $1.17-3.81$ \\
\hline Cholesterol (mmol/l) & $5.17 \pm 0.89$ & $3.76-7.90$ & $4.92 \pm 0.37$ & $4.53-5.62$ \\
\hline HDL-cholesterol (mmol/l) & $1.33 \pm 0.25$ & $0.78-1.68$ & $1.07 \pm 0.28^{\mathrm{a}}$ & $0.82-1.68$ \\
\hline $\operatorname{ApoB}(\mathrm{mg} / \mathrm{dl})$ & $106 \pm 19$ & $66-140$ & $121 \pm 15^{\mathrm{a}}$ & $104-156$ \\
\hline LDL size (nm) & $26.3 \pm 1.0$ & $23.4-27.8$ & $25.2 \pm 1.1^{\mathrm{a}}$ & $23.2-26.4$ \\
\hline
\end{tabular}

ALT Alanine aminotransferase

${ }^{\mathrm{a}} p<0.05,{ }^{\mathrm{b}} p<0.01,{ }^{\mathrm{c}} p<0.001$ vs non-diabetic subjects 


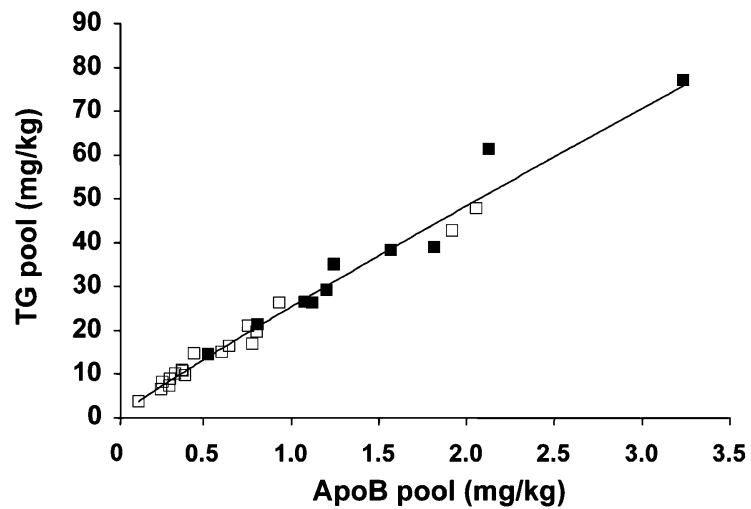

Fig. 1 Measured $\mathrm{VLDL}_{1}$ ApoB pool size plotted against measured VLDL $_{1}$ TG pool sizes in type 2 diabetic subjects (filled boxes, $n=10$ ) and control subjects (open boxes, $n=18$ ). There was a strong linear correlation between the ApoB and TG pools in all subjects $(r=0.98$, $p<0.001)$. This finding is consistent with our earlier results [3]

Vision; Siemens, Erlangen, Germany) using a combination of whole-body and loop surface coils for the radio frequency transmitting and receiving of signals $[9,11]$. Volumes of interest $\left(8 \mathrm{~cm}^{3}\right)$ in the liver were placed, avoiding vascular structures and s.c. fat tissue. These areas were typically within the right lobe. Chemical shifts were measured relative to water signal intensity at $4.8 \mathrm{ppm}$ $\left(\mathrm{S}_{\text {water }}\right)$. Methylene signal intensity, which represents intracellular TGs in the liver [11], was measured at $1.4 \mathrm{ppm}$ $\left(\mathrm{S}_{\mathrm{fat}}\right)$. The measurement of the percentage of hepatic fat by proton spectroscopy has been validated against the lipid content of liver biopsies in humans [26] and against liver density measurements performed by computed tomography [11]. The percentage of liver fat was calculated as $100 \times \mathrm{S}_{\text {fat }} /$
$\left(\mathrm{S}_{\text {fat }}+\mathrm{S}_{\mathrm{water}}\right)$. Regarding the error introduced by the use of a single rather than multiple voxels, we have shown in 24 normal subjects that the Spearman's correlation coefficient for liver fat between the left and right lobes is $0.95(95 \%$ CI $0.89-0.98, p<0.0001)$ and the $\mathrm{CV}$ is $6 \%$.

\section{Determination of intra-abdominal and s.c. fat volumes}

Intra-abdominal and s.c. fat volumes were determined by MRI. A series of $16 \mathrm{~T}_{1}$-weighted transaxial scans were acquired from a region extending from $8 \mathrm{~cm}$ above to $8 \mathrm{~cm}$ below the fourth and fifth lumbar interspaces [11]. Intraabdominal and s.c. fat areas were measured with an image analysis program (Alice 3.0; Parexel, Waltham, MA, USA) [11].

\section{Statistical analysis}

Differences between non-diabetic and type 2 diabetic subjects were evaluated with unpaired, two-sided $t$ tests. Correlations were evaluated by linear regression and multiple interactions by forward stepwise multivariate linear regression and by exhaustive check of all possible multivariate models. Variables with univariate correlation with $p<0.05$ were included in the multivariate regression but HOMA-IR was left out of the multivariate when both plasma glucose and fasting insulin were included. Also, we included all fat compartment variables in the multivariate analysis, even though we did not find a univariate correlation. The correlations were calculated for all subjects as well as for the type 2 diabetic subjects and the non-diabetic subjects. For nonnormally distributed variables, values were log-trans-

Table 2 Calculated parameters

\begin{tabular}{|c|c|c|c|c|}
\hline & \multicolumn{2}{|c|}{ Non-diabetic subjects $(n=18)$} & \multicolumn{2}{|c|}{ Type 2 diabetic subjects $(n=10)$} \\
\hline & Mean $\pm \mathrm{SD}$ & Range & Mean \pm SD & Range \\
\hline VLDL TG total production ( $\mathrm{mg} \mathrm{kg}^{-1} \mathrm{day}^{-1}$ ) & $249 \pm 84$ & $138-387$ & $382 \pm 114^{\mathrm{b}}$ & $194-525$ \\
\hline VLDL $_{1}$ TG production rate $\left(\mathrm{mg} \mathrm{kg}^{-1}\right.$ day $\left.^{-1}\right)$ & $222 \pm 79$ & $107-352$ & $345 \pm 105^{b}$ & $178-495$ \\
\hline VLDL $_{1}$ TG FCR (pools/day) & $14.9 \pm 7.7$ & $4.4-35.3$ & $11.0 \pm 5.2$ & $3.4-21.5$ \\
\hline VLDL $_{1}$ TG FDCR (pools/day) & $10.8 \pm 6.7$ & $3.9-31.2$ & $8.0 \pm 4.3$ & $1.6-17.0$ \\
\hline VLDL $_{1}$ TG FTR (pools/day) & $4.1 \pm 2.0$ & $0.5-8.6$ & $2.9 \pm 1.2$ & $1.3-5.1$ \\
\hline $\mathrm{VLDL}_{1}$ TG to $\mathrm{VLDL}_{2}$ transfer $\left(\mathrm{mg} \mathrm{kg}^{-1}\right.$ day $\left.^{-1}\right)$ & $63.0 \pm 34.6$ & $20.9-146$ & $93.1 \pm 23.3^{\mathrm{a}}$ & $61.5-128$ \\
\hline VLDL $_{2}$ TG direct production rate $\left(\mathrm{mg} \mathrm{kg}^{-1}\right.$ day $\left.^{-1}\right)$ & $27.5 \pm 9.2$ & $14.4-51.4$ & $37.4 \pm 14.7^{\mathrm{a}}$ & $15.6-61.7$ \\
\hline VLDL $_{2}$ TG FCR (pools/day) & $14.9 \pm 8.1$ & $4.4-39.4$ & $12.8 \pm 5.2$ & $6.2-23.7$ \\
\hline VLDL ApoB total production ( $\mathrm{mg} \mathrm{kg}^{-1}$ day $^{-1}$ ) & $9.2 \pm 3.6$ & $4.1-15.1$ & $13.6 \pm 3.6^{\mathrm{b}}$ & $7.4-18.6$ \\
\hline $\mathrm{VLDL}_{1}$ ApoB production rate $\left(\mathrm{mg} \mathrm{kg}^{-1}\right.$ day $\left.^{-1}\right)$ & $7.1 \pm 3.1$ & $2.9-12.5$ & $11.1 \pm 3.5^{\mathrm{b}}$ & $6.4-16.5$ \\
\hline VLDL $_{1}$ ApoB FCR (pools/day) & $12.4 \pm 6.9$ & $4.0-31.0$ & $9.1 \pm 5.1$ & $3.1-21.5$ \\
\hline VLDL $_{1}$ ApoB FDCR (pools/day) & $4.6 \pm 6.0$ & $0.0-23.3$ & $3.8 \pm 3.5$ & $0.0-11.3$ \\
\hline VLDL $_{1}$ ApoB FTR (pools/day) & $7.8 \pm 3.7$ & $1.2-13.4$ & $5.3 \pm 2.7$ & $1.6-10.2$ \\
\hline VLDL $_{1}$ ApoB to VLDL 2 transfer $\left(\mathrm{mg} \mathrm{kg}^{-1}\right.$ day $\left.^{-1}\right)$ & $4.7 \pm 2.6$ & $1.8-10.0$ & $6.2 \pm 1.1$ & $4.2-7.7$ \\
\hline VLDL $_{2}$ ApoB direct production rate $\left(\mathrm{mg} \mathrm{kg}^{-1}\right.$ day $\left.^{-1}\right)$ & $2.1 \pm 0.8$ & $1.0-3.3$ & $2.5 \pm 0.8$ & $1.0-3.5$ \\
\hline VLDL $_{2}$ ApoB FCR (pools/day) & $6.1 \pm 2.9$ & $2.1-12.3$ & $5.7 \pm 2.5$ & $2.3-8.9$ \\
\hline
\end{tabular}

${ }^{\mathrm{a}} p<0.05,{ }^{\mathrm{b}} p<0.01$ vs non-diabetic subjects 
a
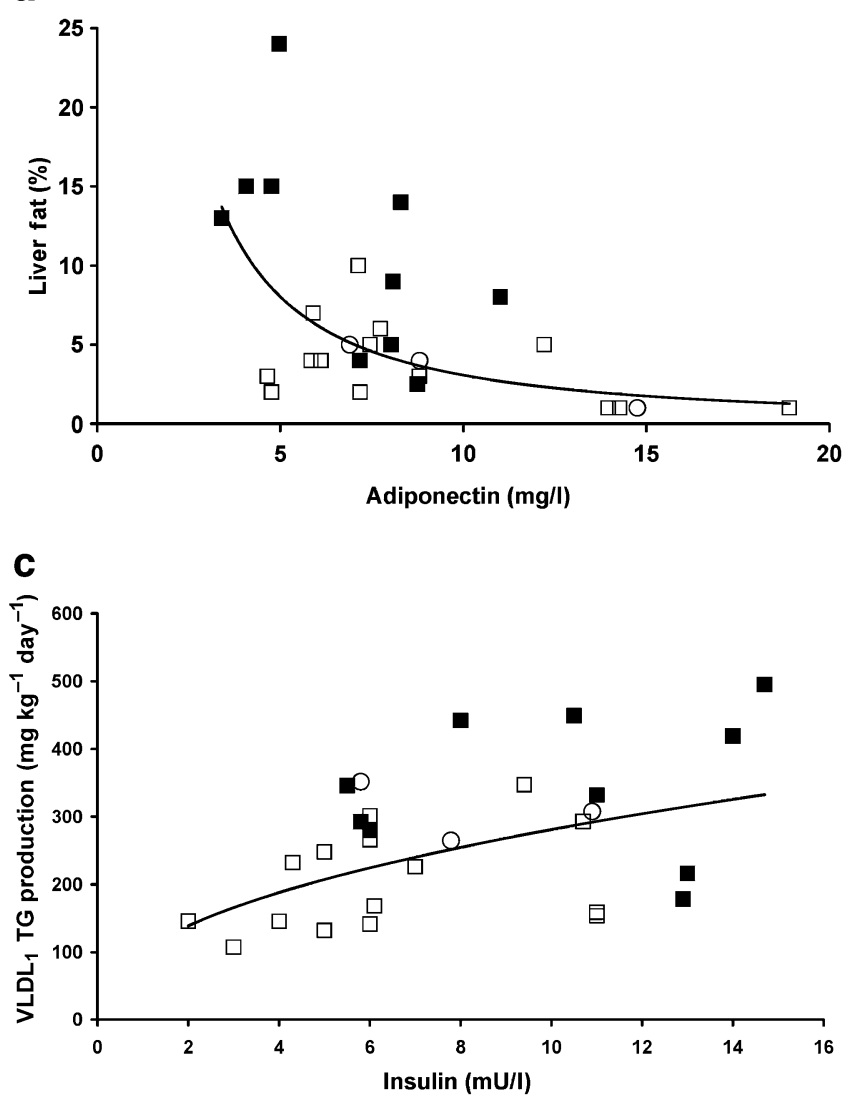

Fig. 2 Correlation between liver fat and a adiponectin (all subjects, $r=-0.65, p<0.001$; non-diabetic subjects, $r=-0.62, p<0.01$; subjects with type 2 diabetes mellitus, $r=-0.59$, NS) and $\mathbf{b}$ intra-abdominal fat (all subjects, $r=0.53, p<0.01$; non-diabetic subjects, $r=0.47$, $p<0.05$; subjects with type 2 diabetes mellitus, $r=0.41$, NS). Correlation between VLDL $_{1}$ TG production and $\mathbf{c}$ plasma insulin (all subjects, $r=0.50, p<0.01$; non-diabetic subjects, $r=0.46$, NS;

formed before correlation analysis. Values of $p<0.05$ were considered significant.

Statistical analysis was performed with SPSS, Microsoft Excel and Matlab (MathWorks, Natick, MA, USA).
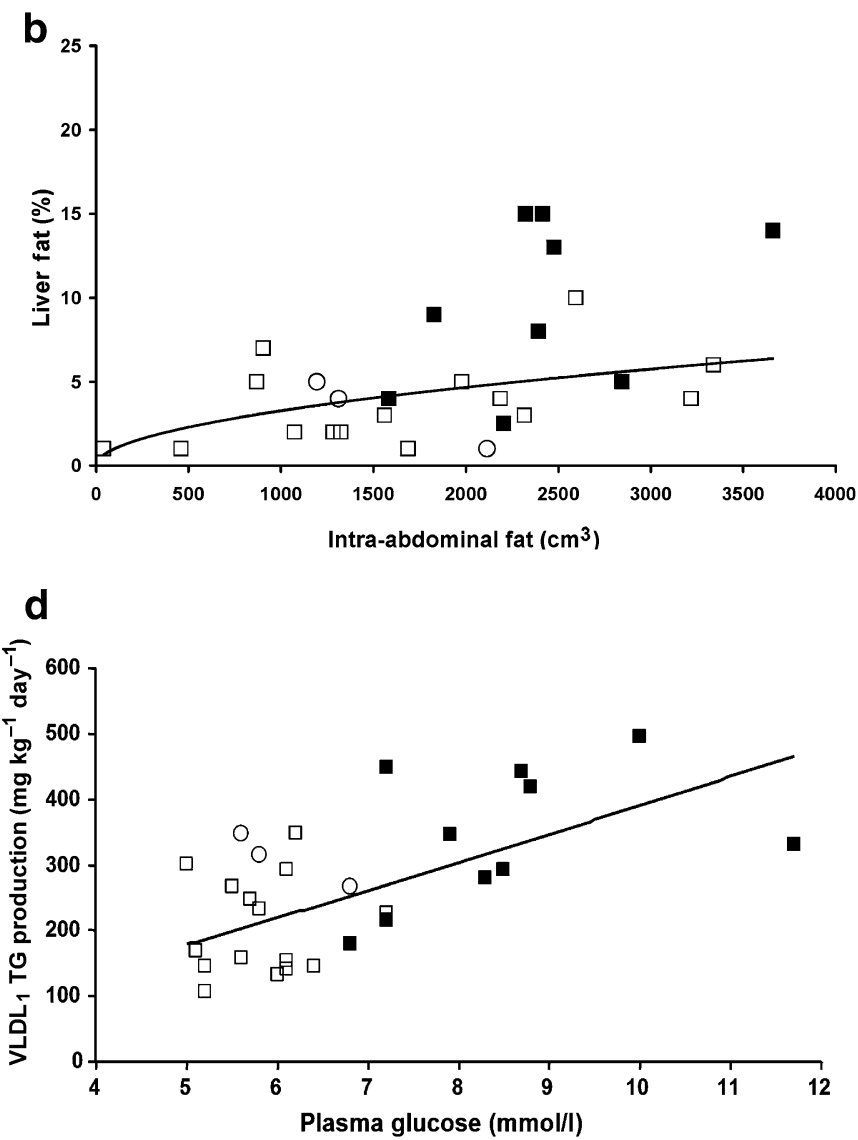

subjects with type 2 diabetes mellitus, $r=-0.04$, NS) and d plasma glucose (all subjects, $r=0.59, \quad p<0.001$; non-diabetic subjects, $r=0.12$, NS; subjects with type 2 diabetes mellitus, $r=0.39$, NS). Filled boxes, subjects with type 2 diabetes mellitus; open boxes, non-diabetic subjects; open circles, IGT subjects. Data were logtransformed before the regression analysis.

\section{Results}

Subject characteristics

Characteristics of the subjects are summarised in Table 1. As expected, type 2 diabetic subjects were more obese than

Table 3 Univariate regressions of plasma concentrations and adiposity measures

\begin{tabular}{lcccccccc}
\hline & Liver fat & Adiponectin & Glucose & Insulin & HOMA-IR & Plasma TG & ApoB & BMI \\
\hline Liver fat & - & $-0.647^{\mathrm{c}}$ & $0.589^{\mathrm{c}}$ & $0.513^{\mathrm{b}}$ & $0.589^{\mathrm{c}}$ & $0.490^{\mathrm{b}}$ & $0.402^{\mathrm{a}}$ & $0.467^{\mathrm{a}}$ \\
NEFA & 0.163 & -0.061 & $0.494^{\mathrm{b}}$ & 0.156 & 0.320 & -0.103 & 0.262 & 0.355 \\
Adiponectin & $-0.647^{\mathrm{c}}$ & - & -0.168 & -0.347 & -0.326 & $-0.445^{\mathrm{a}}$ & -0.348 & -0.275 \\
Glucose & $0.589^{\mathrm{c}}$ & -0.168 & - & $0.511^{\mathrm{b}}$ & $0.793^{\mathrm{c}}$ & 0.258 & 0.295 & $0.427^{\mathrm{a}}$ \\
Insulin & $0.513^{\mathrm{b}}$ & -0.347 & $0.511^{\mathrm{b}}$ & - & $0.955^{\mathrm{c}}$ & $0.501^{\mathrm{b}}$ & $0.393^{\mathrm{a}}$ & $0.666^{\mathrm{c}}$ \\
HOMA-IR & $0.589^{\mathrm{c}}$ & -0.326 & $0.793^{\mathrm{c}}$ & $0.955^{\mathrm{c}}$ & - & $0.479^{\mathrm{b}}$ & $0.407^{\mathrm{a}}$ & $0.656^{\mathrm{c}}$ \\
Total abdominal fat & $0.481^{\mathrm{a}}$ & -0.213 & $0.498^{\mathrm{b}}$ & $0.698^{\mathrm{c}}$ & $0.710^{\mathrm{c}}$ & 0.301 & $0.423^{\mathrm{a}}$ & $0.800^{\mathrm{c}}$ \\
S.c. fat $_{\text {Intra-abdominal fat }}$ & 0.227 & 0.098 & $0.391^{\mathrm{a}}$ & $0.553^{\mathrm{b}}$ & $0.561^{\mathrm{b}}$ & -0.088 & 0.252 & $0.745^{\mathrm{c}}$ \\
\hline
\end{tabular}

Non-normally distributed numbers were log transformed before the analysis $r$ values for univariate regressions ${ }^{\mathrm{a}} p<0.05,{ }^{\mathrm{b}} p<0.01,{ }^{\mathrm{c}} p<0.001$ 
non-diabetic subjects and had a typical dyslipidaemia, with higher plasma TG, lower HDL levels and smaller LDL particles than non-diabetic subjects, and mildly increased plasma glucose, insulin and serum alanine aminotransferase. Type 2 diabetic subjects had a mean glycosylated haemoglobin level of $6.9 \%$ (range $6.1-8.1 \%$, reference range $4-6 \%$ ) and significantly higher hepatic and intraabdominal fat content than non-diabetics subjects. S.c. fat levels were similar in the two groups. Type 2 diabetic subjects had approximately 2.0-fold larger TG and ApoB $\mathrm{VLDL}_{1}$ pools (TG, $20.4 \pm 15.3$ vs $39.8 \pm 21.9 \mathrm{mg} / \mathrm{kg}$; ApoB, $0.8 \pm 0.7$ vs $1.6 \pm 0.9 \mathrm{mg} / \mathrm{kg}$ ) and approximately 1.5 -fold larger $\mathrm{VLDL}_{2}$ pools (TG, $7.4 \pm 3.8$ vs $12.0 \pm 6.5 \mathrm{mg} / \mathrm{kg}$; ApoB, $1.3 \pm 0.7$ vs $1.9 \pm 0.9 \mathrm{mg} / \mathrm{kg}$ ). Importantly, there was a strong linear correlation between the $\mathrm{VLDL}_{1} \mathrm{ApoB}$ and VLDL $_{1}$ TG pools in all subjects $(r=0.98, p<0.001)$ (Fig. 1). Thus, the two groups represent an overlapping continuum of VLDL TG and ApoB pools. The TG:ApoB ratios of $\mathrm{VLDL}_{1}$ and $\mathrm{VLDL}_{2}$ were similar in the two groups.

Production and clearance rates

The $\mathrm{VLDL}_{1}$ and $\mathrm{VLDL}_{2} \mathrm{TG}$ and $\mathrm{ApoB}$ pool sizes and enrichment data were entered into a multicompartment model that simultaneously determined $\mathrm{VLDL}_{1}$ and $\mathrm{VLDL}_{2}$ TG and ApoB kinetics [21]. Type 2 diabetic subjects produced significantly $(p<0.01)$ more $\mathrm{VLDL}_{1} \mathrm{TG}$ and $\mathrm{ApoB}$ than non-diabetic subjects (Table 2), confirming our previous findings [3]. There was also a significant increase $(p=0.04)$ in direct production of $\mathrm{VLDL}_{2}$, TG but no significant difference in direct production of $\mathrm{VLDL}_{2} \mathrm{ApoB}$. The FCR, the FDCR and the FTR did not differ between nondiabetic and type 2 diabetic subjects. Consistent with the
Table 4 Multivariate regression models searching for independent correlates of liver fat content, $\mathrm{VLDL}_{1} \mathrm{TG}$ and $\mathrm{ApoB}$ production, and $\mathrm{VLDL}_{1} \mathrm{TG}$ and ApoB FTR: results of stepwise multivariate regressions

Non-normally distributed numbers were log-transformed before the analysis.

Significance level for excluded variables is the significance it would have if only that variable were added to the model.

The best models found for liver fat, $\mathrm{VLDL}_{1} \mathrm{TG}$ production rate and $\mathrm{VLDL}_{1}$ ApoB production rate were also best among all multivariate models with two independent parameters.

${ }^{a}$ Significant predictor variables; bexcluded variables

\begin{tabular}{|c|c|c|c|}
\hline & Coefficient & Standard error & Significance \\
\hline \multicolumn{4}{|l|}{ Liver fat } \\
\hline Plasma glucose & $1.73^{\mathrm{a}}$ & $0.54^{\mathrm{a}}$ & $0.004^{\mathrm{a}}$ \\
\hline Adiponectin & $-1.16^{\mathrm{a}}$ & $0.27^{\mathrm{a}}$ & $0.000^{\mathrm{a}}$ \\
\hline Insulin & & & $0.16^{\mathrm{b}}$ \\
\hline S.c. fat & & & $0.53^{\mathrm{b}}$ \\
\hline Intra-abdominal fat & & & $0.24^{\mathrm{b}}$ \\
\hline Plasma TG & & & $0.55^{\mathrm{b}}$ \\
\hline BMI & & & $0.32^{\mathrm{b}}$ \\
\hline \multicolumn{4}{|c|}{$\mathrm{VLDL}_{1} \mathrm{TG}$ production rate } \\
\hline Liver fat & $0.22^{\mathrm{a}}$ & $0.085^{\mathrm{a}}$ & $0.018^{\mathrm{a}}$ \\
\hline Plasma glucose & $0.84^{\mathrm{a}}$ & $0.34^{\mathrm{a}}$ & $0.021^{\mathrm{a}}$ \\
\hline Insulin & & & $0.62^{\mathrm{b}}$ \\
\hline Adiponectin & & & $0.79^{\mathrm{b}}$ \\
\hline S.c. fat & & & $0.49^{\mathrm{b}}$ \\
\hline Intra-abdominal fat & & & $0.58^{\mathrm{b}}$ \\
\hline \multicolumn{4}{|c|}{$\mathrm{VLDL}_{1}$ ApoB production rate } \\
\hline Liver fat & $0.22^{\mathrm{a}}$ & $0.10^{\mathrm{a}}$ & $0.039^{\mathrm{a}}$ \\
\hline Plasma glucose & $1.03^{\mathrm{a}}$ & $0.40^{\mathrm{a}}$ & $0.016^{\mathrm{a}}$ \\
\hline Insulin & & & $0.36^{\mathrm{b}}$ \\
\hline Adiponectin & & & $0.91^{\mathrm{b}}$ \\
\hline S.c. fat & & & $0.69^{\mathrm{b}}$ \\
\hline Intra-abdominal fat & & & $0.43^{\mathrm{b}}$ \\
\hline \multicolumn{4}{|l|}{$\mathrm{VLDL}_{1}$ TG FTR } \\
\hline Insulin & $-0.50^{\mathrm{a}}$ & $0.22^{\mathrm{a}}$ & $0.031^{\mathrm{a}}$ \\
\hline Adiponectin & & & $0.32^{\mathrm{b}}$ \\
\hline Plasma glucose & & & $0.92^{\mathrm{b}}$ \\
\hline Liver fat & & & $0.34^{\mathrm{b}}$ \\
\hline S.c. fat & & & $0.62^{\mathrm{b}}$ \\
\hline Intra-abdominal fat & & & $0.41^{\mathrm{b}}$ \\
\hline \multicolumn{4}{|l|}{$\mathrm{VLDL}_{1}$ ApoB FTR } \\
\hline Insulin & $-0.56^{\mathrm{a}}$ & $0.23^{\mathrm{a}}$ & $0.024^{\mathrm{a}}$ \\
\hline Adiponectin & & & $0.39^{\mathrm{b}}$ \\
\hline Plasma glucose & & & $0.79^{\mathrm{b}}$ \\
\hline Liver fat & & & $0.29^{\mathrm{b}}$ \\
\hline S.c. fat & & & $0.17^{\mathrm{b}}$ \\
\hline Intra-abdominal fat & & & $0.56^{\mathrm{b}}$ \\
\hline
\end{tabular}


conversion of large $\mathrm{VLDL}_{1}$ particles to small dense LDL, the $\mathrm{VLDL}_{1} \mathrm{TG}(p<0.01)$ and ApoB $(p<0.05)$ production rates correlated inversely with LDL size.

Hepatic lipid and intra-abdominal fat predictors

In the univariate regression analysis, liver fat correlated negatively with adiponectin (Fig. 2a) and positively with plasma glucose, plasma TG, insulin, alanine aminotransferase and HOMA-IR $(p<0.01)$, but less strongly with plasma ApoB and BMI (Table 3). Liver fat also correlated positively with intra-abdominal fat (Fig. 2b) and total abdominal fat (Table 3). All fat compartments were highly correlated with BMI (Table 3). Notably, intra-abdominal fat correlated positively with s.c. fat $(r=0.59, p<0.001)$. In a multivariate regression analysis, only adiponectin and plasma glucose were independently associated with liver fat (Table 4). Intra-abdominal fat also correlated strongly with insulin and HOMA-IR, but less strongly with plasma glucose, TG and ApoB.
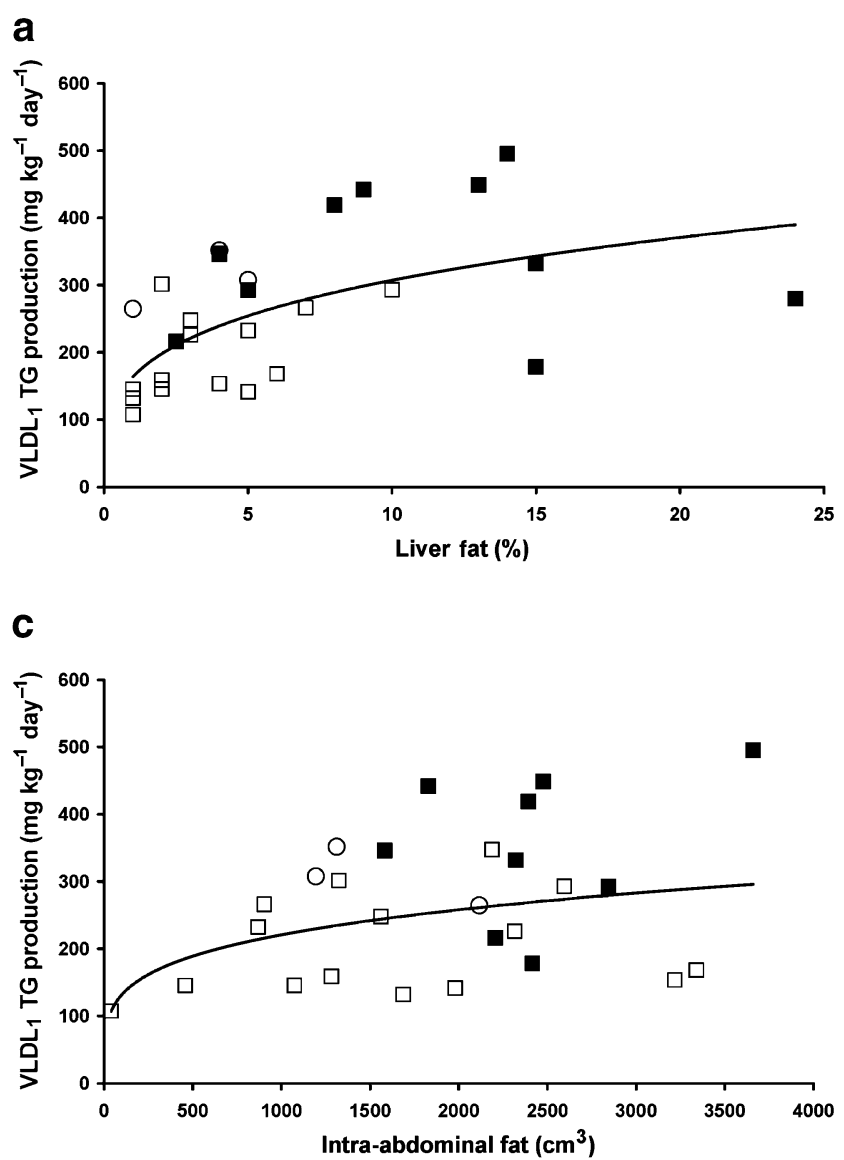

Fig. 3 Correlation between liver fat and a $\mathrm{VLDL}_{1} \mathrm{TG}$ production (all subjects, $r=-0.58, p<0.01$; non-diabetic subjects, $r=0.48$, $p<0.05$; subjects with type 2 diabetes mellitus, $r=0.17$, NS) and b VLDL 1 ApoB production (all subjects, $r=0.52, p<0.01$; nondiabetic subjects, $r=0.41, p=0.09$; subjects with type 2 diabetes mellitus, $r=0.06$, NS). Correlation between intra-abdominal fat and c VLDL 1 TG production (all subjects, $r=0.46, p<0.05$; non-diabetic
Production and clearance rates

Univariate regression analysis showed that liver fat correlated positively with $\mathrm{VLDL}_{1} \mathrm{TG}$ and $\mathrm{ApoB}$ production rates $(p<0.01)$ (Fig. 3a,b Table 5). Liver fat also showed a weak negative correlation with $\mathrm{VLDL}_{1}$ ApoB and TG FTRs $(p<0.05)$. VLDL 1 TG production rate also correlated with plasma glucose, insulin $(p<0.01)$ (Fig. $2 \mathrm{c}, \mathrm{d})$ and HOMA-IR $(p<0.001)$; the same correlation was observed for the $\mathrm{VLDL}_{1}$ ApoB production rate, consistent with earlier results [3]. Intra-abdominal fat correlated positively with $\mathrm{VLDL}_{1}$ TG and ApoB production rates $(p<0.05)$ (Fig. $3 \mathrm{c}, \mathrm{d})$ and negatively with VLDL 2 TG and ApoB FTR $(p<0.05)$. Adiponectin correlated negatively with $\mathrm{VLDL}_{1} \mathrm{TG}$ and ApoB pool sizes $(p<0.01)$ and positively with the corresponding FCR $(p<0.05)$ but was not linked to $\mathrm{VLDL}_{1}$ TG or ApoB production rates.

In a stepwise multivariate regression analysis of $\mathrm{VLDL}_{1}$ TG or ApoB production rate as the dependent variable and plasma glucose, insulin, liver fat, intra-abdominal fat, subcutaneous fat and adiponectin as independent variables,
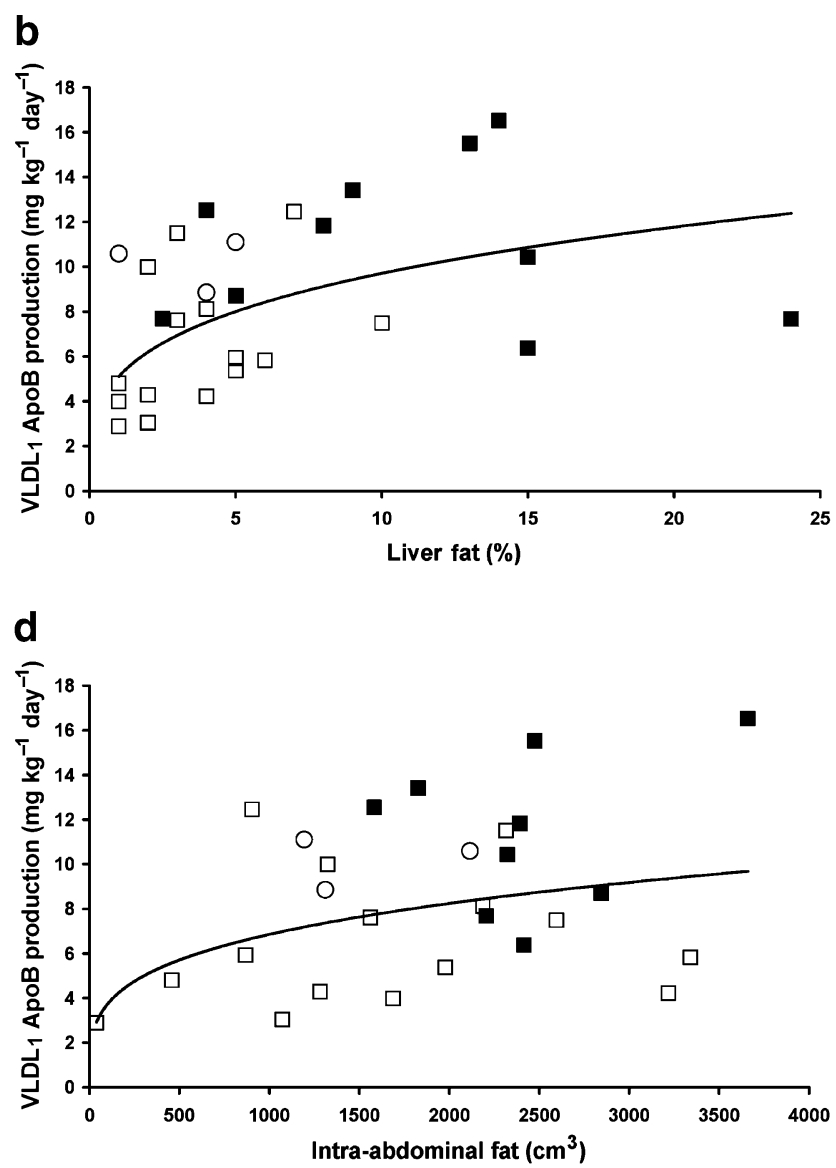

subjects, $r=0.40$, NS; subjects with type 2 diabetes mellitus, $r=0.14$, NS) and d VLDL 1 ApoB production (all subjects, $r=0.47, p<0.05$; non-diabetic subjects, $r=0.41, \mathrm{NS}$; subjects with type 2 diabetes mellitus, $r=0.10$, NS). Filled boxes, subjects with type 2 diabetes mellitus; open boxes, non-diabetic subjects; open circles, IGT subjects. Data were log-transformed prior to the regression analysis 
only plasma glucose and liver fat remained significant (Table 4). When $\mathrm{VLDL}_{1}$ TG or ApoB FTR served as the independent variable, insulin was the best predictor of VLDL $_{1}$ TG and ApoB (Table 4).

\section{Discussion}

This study shows that liver fat, insulin and plasma glucose are independent determinants of $\mathrm{VLDL}_{1} \mathrm{TG}$ and $\mathrm{ApoB}$ production rates. The key metabolic determinants of liver fat content were intra-abdominal fat, adiponectin and plasma glucose. These findings emphasise the critical role of substrate fluxes and lipid availability in the liver as the driving force for the overproduction of $\mathrm{VLDL}_{1}$ in subjects with type 2 diabetes [21].

The liver fat content reflects the balance between NEFA flux, fatty acid oxidation, de novo lipogenesis and VLDL secretion. Increased NEFA flux is a major contributor to the availability of TG for VLDL assembly [27, 28]. Indeed, increased delivery of NEFA to the liver in humans is associated with fatty liver $[29,30]$ and has been linked to hepatic insulin resistance [31-33]. These findings are consistent with the strong relationship we observed between intra-abdominal fat and liver fat content.

Both hepatic and intra-abdominal fat content correlated with $\mathrm{VLDL}_{1}$ TG and ApoB production rates in the univariate analysis, but only the hepatic fat content was significant in multiple regression models. Our data suggest that hepatic steatosis is the proximate cause of the characteristic atherogenic dyslipidaemia seen in type 2 diabetes $[1,10]$. This conclusion is consistent with the fact that VLDL is produced by liver fat, not visceral adipose tissue. $\mathrm{VLDL}_{1}$ particles are converted in the circulation by cholesteryl ester transport protein and hepatic lipase - which are commonly increased in type 2 diabetes - to small atherogenic LDL particles [1]. This explains the strong inverse correlation between $\mathrm{VLDL}_{1} \mathrm{TG}$ production rate and LDL particle size. In a parallel process, excess of $\mathrm{VLDL}_{1}$ particles alters the lipid composition of HDL particles, leading to enhanced catabolism of these particles [34]; this explains the strong inverse correlation between HDLcholesterol and liver fat in the present study $(p<0.001$, $r=-0.65)$. Thus, overexpression of $\mathrm{VLDL}_{1}$ leads to the generation of both small dense LDL and low HDL, the two hallmarks of diabetic dyslipidaemia. Our data highlight liver fat as a major driving force for diabetic dyslipidaemia. However, we recognise that regulatory factors not measurable in man (i.e. enzymatic activities in the liver, transcription factors and substrate fluxes) can influence hepatic lipid metabolism and influence VLDL production.

The correlation of the direct production rates of both $\mathrm{VLDL}_{2} \mathrm{TG}$ and $\mathrm{ApoB}$ with liver fat content suggests that excessive accumulation of hepatic fat also influences the $\mathrm{VLDL}_{2}$ production rate (Table 5).

Insulin appears to be pivotal in regulating VLDL assembly in the liver [35, 36]. Insulin acts on two key factors that regulate the initiation of VLDL assembly and the maturation of VLDL particles: microsomal triglyceride transfer protein and phosphatidylinositol 3-kinase [37-40]. Consequently, impaired insulin signalling results in increased VLDL production. Consistent with previous studies $[3,41]$, we observed significant relationships between fasting insulin and HOMA-IR and $\mathrm{VLDL}_{1}$ TG and ApoB production rates. However, these relationships were not significant in regression models that included liver fat. HOMA-IR can be considered at best a surrogate marker for type 2 diabetes, and, notably, is influenced more strongly by fasting glucose than by insulin, since fasting glucose closely reflects hepatic glucose production [42]. Thus, liver fat content may influence hepatic insulin resistance by blunting the insulin signalling pathways in the liver. This would explain why fasting glucose predicted $\mathrm{VLDL}_{1}$ production, especially in subjects with type 2 diabetes (Fig. 2 d).

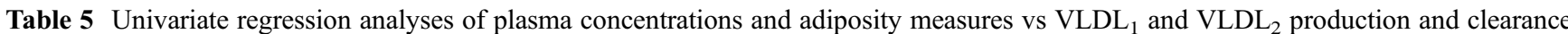
rates

\begin{tabular}{|c|c|c|c|c|c|c|c|c|c|c|}
\hline & \multicolumn{5}{|l|}{ TG } & \multicolumn{5}{|l|}{ ApoB } \\
\hline & $\begin{array}{l}\text { VLDL }_{1} \\
\text { FCR }\end{array}$ & $\begin{array}{l}\text { VLDL }_{1} \\
\text { FTR }\end{array}$ & $\begin{array}{l}\mathrm{VLDL}_{1} \\
\text { production } \\
\text { rate }\end{array}$ & $\begin{array}{l}\mathrm{VLDL}_{2} \\
\text { FCR }\end{array}$ & $\begin{array}{l}\mathrm{VLDL}_{2} \\
\mathrm{DPR}\end{array}$ & $\begin{array}{l}\mathrm{VLDL}_{1} \\
\text { FCR }\end{array}$ & $\begin{array}{l}\text { VLDL }_{1} \\
\text { FTR }\end{array}$ & $\begin{array}{l}\mathrm{VLDL}_{1} \\
\text { production } \\
\text { rate }\end{array}$ & $\begin{array}{l}\mathrm{VLDL}_{2} \\
\text { FCR }\end{array}$ & $\begin{array}{l}\mathrm{VLDL}_{2} \\
\mathrm{DPR}\end{array}$ \\
\hline Liver fat & -0.349 & $-0.392^{\mathrm{a}}$ & $0.583^{\mathrm{b}}$ & -0.307 & $0.392^{\mathrm{a}}$ & $-0.405^{\mathrm{a}}$ & $-0.416^{\mathrm{a}}$ & $0.523^{\mathrm{b}}$ & -0.249 & $0.439^{\mathrm{a}}$ \\
\hline NEFA & 0.128 & -0.125 & 0.317 & -0.165 & 0.050 & 0.192 & 0.060 & $0.378^{\mathrm{a}}$ & 0.121 & 0.146 \\
\hline Adiponectin & $0.402^{\mathrm{a}}$ & 0.377 & -0.355 & 0.343 & $-0.418^{\mathrm{a}}$ & $0.436^{\mathrm{a}}$ & 0.300 & -0.272 & 0.350 & $-0.467^{\mathrm{a}}$ \\
\hline Glucose & -0.120 & -0.326 & $0.593^{\mathrm{c}}$ & -0.160 & $0.437^{\mathrm{a}}$ & -0.081 & -0.369 & $0.568^{\mathrm{b}}$ & -0.094 & 0.356 \\
\hline Insulin & $-0.401^{\mathrm{a}}$ & $-0.449^{\mathrm{a}}$ & $0.505^{\mathrm{b}}$ & -0.263 & 0.282 & -0.359 & $-0.487^{\mathrm{b}}$ & $0.540^{\mathrm{b}}$ & -0.259 & 0.271 \\
\hline HOMA-IR & -0.348 & $-0.422^{\mathrm{a}}$ & $0.594^{\mathrm{c}}$ & -0.219 & 0.368 & -0.296 & $-0.487^{\mathrm{b}}$ & $0.617^{\mathrm{c}}$ & -0.206 & 0.331 \\
\hline Total abdominal fat & -0.216 & $-0.398^{\mathrm{a}}$ & 0.346 & -0.364 & -0.047 & -0.135 & -0.347 & $0.430^{\mathrm{a}}$ & -0.235 & -0.048 \\
\hline S.c. fat & -0.155 & -0.268 & 0.115 & -0.253 & -0.213 & -0.012 & -0.128 & 0.258 & -0.010 & -0.105 \\
\hline Intra-abdominal fat & -0.266 & $-0.382^{\mathrm{a}}$ & $0.459^{\mathrm{a}}$ & $-0.438^{\mathrm{a}}$ & 0.127 & -0.252 & $-0.415^{\mathrm{a}}$ & $0.474^{\mathrm{a}}$ & $-0.392^{\mathrm{a}}$ & 0.129 \\
\hline
\end{tabular}

Non-normally distributed numbers were log transformed before the analysis

$r$ values for univariate regressions

${ }^{\mathrm{a}} p<0.05,{ }^{\mathrm{b}} p<0.01,{ }^{\mathrm{c}} p<0.001$

$D P R$ Direct production rate 
The strong relation between fasting glucose and $\mathrm{VLDL}_{1}$ production probably reflects disturbed regulation of $\mathrm{VLDL}_{1}$ production. The relation between plasma glucose and VLDL 1 TG production could be explained by increased expression of sterol regulatory element binding protein $1 \mathrm{c}$ (SREBP1c) because of the increased levels of insulin combined with increased production of glycerol 3-phosphate. Glycerol 3-phosphate could either be formed during the glycolysis, but more probably as a result of the increased gluconeogenesis present in insulin resistance. The observation that fasting glucose in insulin resistance is closely linked to the production of glucose in the liver would support such a mechanism.

Elevated plasma glucose concentrations may also contribute directly to increased $\mathrm{VLDL}_{1}$ production by providing the carbon skeleton for glycerol utilised in the reesterification of NEFA. Therefore, in the setting of increased NEFA flux, hyperglycaemia may enhance TG synthesis. Along these lines, it has been indicated that glucose could influence the bulk lipid addition step of VLDL assembly [43]. Another potential source of liver TG is de novo lipogenesis [29, 30]. In liver insulin resistance, hyperinsulinaemia upregulates SREBP1c expression and leads to activation of key enzymes for lipogenesis [44, 45]. Carbohydrate responsive-element binding protein (ChREBP) is also stimulated by hyperglycaemia and activates key lipogenic enzymes [46]. Thus, concomitant upregulation of SREBP $1 \mathrm{c}$ and ChREBP by insulin and glucose in type 2 diabetes can increase hepatic lipogenesis. Production of malonyl-CoA is increased by fatty acid synthesis, but is also increased directly by acetyl-CoA carboxylase-2, which is activated by SREBP1c. Malonyl-CoA inhibits carnitine palmitoyl transferase-1, which results in decreased fatty acid oxidation $[47,48]$. Thus, elevated plasma glucose acts via multiple pathways to increase liver fat content. Not surprising, plasma glucose strongly correlated with both liver fat content and $\mathrm{VLDL}_{1}$ production rate.

Adiponectin also appears to contribute to the metabolic dysregulation in type 2 diabetes. Adiponectin strongly predicted liver fat content, as in previous studies [16]. By activating AMP-activated protein kinase in hepatocytes [49], which stimulates $\beta$-oxidation and simultaneously inhibits lipogenesis [50], adiponectin may regulate fatty acid oxidation. By activating peroxisome proliferator activated receptor (PPAR) $\alpha$, adiponectin may be pivotal in upregulating the expression of key enzymes of fatty acid oxidation [14]. Thus, hypoadiponectinaemia in type 2 diabetes may impair fatty acid oxidation through at least two mechanisms. In the setting of increased NEFA flux, this would direct NEFA for re-esterification and enhance TG accumulation in the liver.

Several studies have reported a strong association between dyslipidaemia and adiponectin. Despite the close relationship between adiponectin and the liver fat content, adiponectin did not predict $\mathrm{VLDL}_{1}$ production and therefore must influence plasma TGs by mechanisms other than effects on $\mathrm{VLDL}_{1}$ production. Interestingly, adiponectin regulates plasma lipoprotein lipase activity independently of insulin sensitivity and BMI [51]. Thus, adiponectin can influence the intravascular catabolism of VLDL particles by several mechanisms. This hypothesis is consistent with our finding that adiponectin correlated with the FCR of $\mathrm{VLDL}_{1} \mathrm{TG}$ and ApoB and the FTR of VLDL $\mathrm{VL}_{1} \mathrm{TG}$, and is consistent with recent data by $\mathrm{Ng}$ et al. [52]. Notably, adiponectin stimulates (via its action on $\operatorname{PPAR} \alpha$ ) the expression of Apo-CIII, which regulates the metabolism of TGs [53].

A potential weakness of our study is that the data are derived from two populations with different characteristics. Thus, the reported findings could be a function of the predictors or of the diabetic state in itself. However, the two groups are not entirely separate but represent an overlapping continuum of VLDL TG and ApoB pools.

In summary, we propose that the metabolic effect of insulin resistance, partly mediated by depressed plasma adiponectin levels, increases fatty acid flux from adipose tissue to the liver and induces the accumulation of fat in the liver. Elevated plasma glucose can further increase hepatic fat content though multiple pathways, resulting in overproduction of $\mathrm{VLDL}_{1}$ particles and leading to the characteristic dyslipidaemia associated with type 2 diabetes.

Acknowledgements We thank H. Hilden, H. Perttunen-Nio, K. Skålén and D. Bedford for expert technical assistance and S. Ordway for editing the manuscript. This work was supported by The Swedish Research Council, The Swedish Heart-Lung Foundation, The Göran Gustafsson Foundation, The Sigrid Juselius Foundation and the Helsinki University Central Hospital Research Foundation.

\section{References}

1. Taskinen MR (2003) Diabetic dyslipidaemia: from basic research to clinical practice. Diabetologia 46:733-749

2. Hiukka A, Fruchart J, Leinonen E, Hilden H, Fruchart J, Taskinen M (2005) Alterations of lipids and apolipoprotein CIII in VLDL subspecies in type 2 diabetes. Diabetologia 48:12071215

3. Adiels M, Boren J, Caslake M et al (2005) Overproduction of VLDL1 driven by hyperglycemia is a dominant feature of diabetic dyslipidemia. Arterioscler Thromb Vasc Biol 25:16971703

4. Marchesini G, Brizi M, Bianchi G et al (2001) Nonalcoholic fatty liver disease: a feature of the metabolic syndrome. Diabetes 50:1844-1850

5. Vozarova B, Stefan N, Lindsay RS et al (2002) High alanine aminotransferase is associated with decreased hepatic insulin sensitivity and predicts the development of type 2 diabetes. Diabetes 51:1889-1895

6. Hanley AJ, Williams K, Festa A et al (2004) Elevations in markers of liver injury and risk of type 2 diabetes: the insulin resistance atherosclerosis study. Diabetes 53:2623-2632

7. Yki-Jarvinen H, Westerbacka J (2005) The fatty liver and insulin resistance. Curr Mol Med 5:287-295

8. Seppala-Lindroos A, Vehkavaara S, Hakkinen AM et al (2002) Fat accumulation in the liver is associated with defects in insulin suppression of glucose production and serum free fatty acids independent of obesity in normal men. J Clin Endocrinol Metab 87:3023-3028 
9. Westerbacka J, Corner A, Tiikkainen M et al (2004) Women and men have similar amounts of liver and intra-abdominal fat, despite more subcutaneous fat in women: implications for sex differences in markers of cardiovascular risk. Diabetologia 47:1360-1369

10. Kelley DE, McKolanis TM, Hegazi RA, Kuller LH, Kalhan SC (2003) Fatty liver in type 2 diabetes mellitus: relation to regional adiposity, fatty acids, and insulin resistance. Am J Physiol Endocrinol Metab 285:E906-E916

11. Ryysy L, Hakkinen AM, Goto T et al (2000) Hepatic fat content and insulin action on free fatty acids and glucose metabolism rather than insulin absorption are associated with insulin requirements during insulin therapy in type 2 diabetic patients. Diabetes 49:749-758

12. Nielsen S, Guo Z, Johnson CM, Hensrud DD, Jensen MD (2004) Splanchnic lipolysis in human obesity. J Clin Invest 113:1582-1588

13. Nieves DJ, Cnop M, Retzlaff B et al (2003) The atherogenic lipoprotein profile associated with obesity and insulin resistance is largely attributable to intra-abdominal fat. Diabetes 52:172-179

14. Matsuzawa Y, Funahashi T, Kihara S, Shimomura I (2004) Adiponectin and metabolic syndrome. Arterioscler Thromb Vasc Biol 24:29-33

15. Shimabukuro M, Higa N, Asahi T et al (2003) Hypoadiponectinemia is closely linked to endothelial dysfunction in man. $\mathrm{J}$ Clin Endocrinol Metab 88:3236-3240

16. Bajaj M, Suraamornkul S, Piper P et al (2004) Decreased plasma adiponectin concentrations are closely related to hepatic fat content and hepatic insulin resistance in pioglitazone-treated type 2 diabetic patients. J Clin Endocrinol Metab 89:200-206

17. Tschritter O, Fritsche A, Thamer C et al (2003) Plasma adiponectin concentrations predict insulin sensitivity of both glucose and lipid metabolism. Diabetes 52:239-243

18. Pellme F, Smith U, Funahashi T et al (2003) Circulating adiponectin levels are reduced in nonobese but insulin-resistant first-degree relatives of type 2 diabetic patients. Diabetes 52:1182-1186

19. Cnop M, Havel PJ, Utzschneider KM et al (2003) Relationship of adiponectin to body fat distribution, insulin sensitivity and plasma lipoproteins: evidence for independent roles of age and sex. Diabetologia 46:459-469

20. Cote M, Mauriege P, Bergeron J et al (2005) Adiponectinemia in visceral obesity: impact on glucose tolerance and plasma lipoprotein and lipid levels in men. J Clin Endocrinol Metab 90:1434-1439

21. Adiels M, Packard C, Caslake MJ et al (2005) A new combined multicompartmental model for apolipoprotein B-100 and triglyceride metabolism in VLDL subfractions. J Lipid Res 46:58-67

22. World Health Organization (1999) Report of a WHO Consultation. Definition, diagnosis and classification of diabetes mellitus and its complications. Part 1: Diagnosis and classification of diabetes mellitus. Department of Noncommunicable Disease Surveillance. World Health Organization, Geneva

23. Lindgren F, Jensen L (1972) The isolation and quantitative analysis of serum lipoproteins. In: Nelson GJ (ed.) Blood lipids and lipoproteins: quantification, composition and metabolism. Wiley, Livermore, CA, pp 182-217

24. Vakkilainen J, Jauhiainen M, Ylitalo K et al (2002) LDL particle size in familial combined hyperlipidemia: effects of serum lipids, lipoprotein-modifying enzymes, and lipid transfer proteins. J Lipid Res 43:598-603

25. Wallace TM, Levy JC, Matthews DR (2004) Use and abuse of HOMA modeling. Diabetes Care 27:1487-1495

26. Thomsen C, Becker U, Winkler K, Christoffersen P, Jensen M, Henriksen O (1994) Quantification of liver fat using magnetic resonance spectroscopy. Magn Reson Imaging 12:487-495
27. Zhang YL, Hernandez-Ono A, Ko C, Yasunaga K, Huang LS, Ginsberg HN (2004) Regulation of hepatic apolipoprotein B-lipoprotein assembly and secretion by the availability of fatty acids. I. Differential response to the delivery of fatty acids via albumin or remnant-like emulsion particles. J Biol Chem 279:19362-19374

28. Lewis GF, Carpentier A, Adeli K, Giacca A (2002) Disordered fat storage and mobilization in the pathogenesis of insulin resistance and type 2 diabetes. Endocr Rev 23:201-229

29. Donnelly KL, Smith CI, Schwarzenberg SJ, Jessurun J, Boldt MD, Parks EJ (2005) Sources of fatty acids stored in liver and secreted via lipoproteins in patients with nonalcoholic fatty liver disease. J Clin Invest 115:1343-1351

30. Tamura S, Shimomura I (2005) Contribution of adipose tissue and de novo lipogenesis to nonalcoholic fatty liver disease. J Clin Invest 115:1139-1142

31. Boden G (1997) Role of fatty acids in the pathogenesis of insulin resistance and NIDDM. Diabetes 46:3-10

32. McGarry JD (2002) Banting lecture 2001: dysregulation of fatty acid metabolism in the etiology of type 2 diabetes. Diabetes 51:7-18

33. Gastaldelli A, Miyazaki Y, Pettiti M et al (2004) Separate contribution of diabetes, total fat mass, and fat topography to glucose production, gluconeogenesis, and glycogenolysis. J Clin Endocrinol Metab 89:3914-3921

34. Rashid S, Watanabe T, Sakaue T, Lewis GF (2003) Mechanisms of HDL lowering in insulin resistant, hypertriglyceridemic states: the combined effect of HDL triglyceride enrichment and elevated hepatic lipase activity. Clin Biochem 36:421-429

35. Malmstrom R, Packard CJ, Caslake M et al (1997) Defective regulation of triglyceride metabolism by insulin in the liver in NIDDM. Diabetologia 40:454-462

36. Zoltowska M, Ziv E, Delvin E, Lambert M, Seidman E, Levy E (2004) Both insulin resistance and diabetes in Psammomys obesus upregulate the hepatic machinery involved in intracellular VLDL assembly. Arterioscler Thromb Vasc Biol 24:118123

37. Carpentier A, Taghibiglou C, Leung N et al (2002) Ameliorated hepatic insulin resistance is associated with normalization of microsomal triglyceride transfer protein expression and reduction in very low density lipoprotein assembly and secretion in the fructose-fed hamster. J Biol Chem 277:28795-28802

38. Au WS, Kung HF, Lin MC (2003) Regulation of microsomal triglyceride transfer protein gene by insulin in HepG2 cells: roles of MAPKerk and MAPKp38. Diabetes 52:1073-1080

39. Phung TL, Roncone A, Jensen KL, Sparks CE, Sparks JD (1997) Phosphoinositide 3-kinase activity is necessary for insulin-dependent inhibition of apolipoprotein B secretion by rat hepatocytes and localizes to the endoplasmic reticulum. J Biol Chem 272:30693-30702

40. Brown AM, Gibbons GF (2001) Insulin inhibits the maturation phase of VLDL assembly via a phosphoinositide 3-kinasemediated event. Arterioscler Thromb Vasc Biol 21:1656-1661

41. Gill JM, Brown JC, Bedford D et al (2004) Hepatic production of VLDL1 but not VLDL2 is related to insulin resistance in normoglycaemic middle-aged subjects. Atherosclerosis 176:49-56

42. Bavenholm PN, Pigon J, Ostenson CG, Efendic S (2001) Insulin sensitivity of suppression of endogenous glucose production is the single most important determinant of glucose tolerance. Diabetes 50:1449-1454

43. Brown AM, Wiggins D, Gibbons GF (1999) Glucose phosphorylation is essential for the turnover of neutral lipid and the second stage assembly of triacylglycerol-rich ApoB-containing lipoproteins in primary hepatocyte cultures. Arterioscler Thromb Vasc Biol 19:321-329

44. Shimomura I, Bashmakov Y, Horton JD (1999) Increased levels of nuclear SREBP-1c associated with fatty livers in two mouse models of diabetes mellitus. J Biol Chem 274:30028-30032 
45. Browning JD, Horton JD (2004) Molecular mediators of hepatic steatosis and liver injury. J Clin Invest 114:147-152

46. Koo SH, Dutcher AK, Towle HC (2001) Glucose and insulin function through two distinct transcription factors to stimulate expression of lipogenic enzyme genes in liver. J Biol Chem 276:9437-9445

47. Gibbons GF, Wiggins D, Brown AM, Hebbachi AM (2004) Synthesis and function of hepatic very-low-density lipoprotein. Biochem Soc Trans 32:59-64

48. Schwarz JM, Linfoot P, Dare D, Aghajanian K (2003) Hepatic de novo lipogenesis in normoinsulinemic and hyperinsulinemic subjects consuming high-fat, low-carbohydrate and low-fat, high-carbohydrate isoenergetic diets. Am J Clin Nutr 77:43-50

49. Yamauchi T, Kamon J, Minokoshi Y et al (2002) Adiponectin stimulates glucose utilization and fatty-acid oxidation by activating AMP-activated protein kinase. Nat Med 8:1288-1295
50. Yamauchi T, Kamon J, Ito Y et al (2003) Cloning of adiponectin receptors that mediate antidiabetic metabolic effects. Nature 423:762-769

51. von Eynatten M, Schneider JG, Humpert PM et al (2004) Decreased plasma lipoprotein lipase in hypoadiponectinemia: an association independent of systemic inflammation and insulin resistance. Diabetes Care 27:2925-2929

52. Ng TW, Watts GF, Farvid MS, Chan DC, Barrett PH (2005) Adipocytokines and VLDL metabolism: independent regulatory effects of adiponectin, insulin resistance, and fat compartments on VLDL apolipoprotein B-100 kinetics? Diabetes $54: 795-802$

53. Chan DC, Watts GF, Ng TW et al (2005) Adiponectin and other adipocytokines as predictors of markers of triglyceride-rich lipoprotein metabolism. Clin Chem 51:578-585 